\title{
Wheat bread enriched with raspberry and strawberry oilcakes: effects on proximate composition, texture and water properties
}

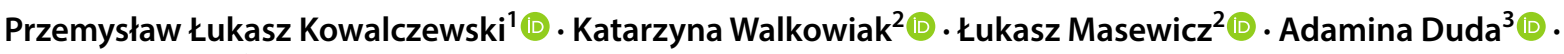

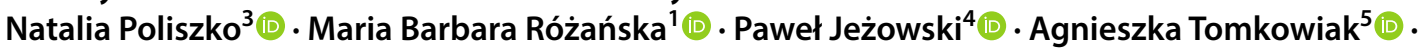 \\ Sylwia Mildner-Szkudlarz ${ }^{1}\left[\right.$ ] Hanna Maria Baranowska² ${ }^{2}$
}

Received: 1 April 2019 / Revised: 7 August 2019 / Accepted: 14 September 2019 / Published online: 3 October 2019

(C) The Author(s) 2019

\begin{abstract}
Oilcakes from the oilseed industry are rich in dietary fibre and protein by-products. We assessed the impact of wheat flour replacement with raspberry and strawberry oilcakes on the proximate composition of bread, colour, texture and water behaviour. The substitution influenced the ash, fat and protein content causing an increase in the content of each of the analysed macronutrients. The crumb colour components (CIE $L^{*} a^{*} b^{*}$ ) were shifted toward red while the saturation of yellow decreased. Texture analysis showed that the hardness and chewiness of crumb with oilcakes increased as well as springiness decreased. It was found that flour substitution with oilcakes limited significantly water transport and also influenced the molecular dynamics of water in the bread crumb. ${ }^{1} \mathrm{H}$ NMR measurement results of relaxation times demonstrated that the free water in relation to the bound water in the examined systems depended on the amount of the flour replaced by the oilcake, as well as on the botanical origin of the oilcakes.
\end{abstract}

Keywords By-products $\cdot$ Defatted seeds $\cdot$ Food enrichment $\cdot$ Low-field NMR $\cdot$ Water activity $\cdot$ Water dynamics

\section{Introduction}

Bread is one of the most popular cereal food products in the world. Due to its universal character and volume of consumption, it is possible to introduce new nutritional and bioactive compounds into the diet through the use of

Electronic supplementary material The online version of this article (https://doi.org/10.1007/s00217-019-03370-5) contains supplementary material, which is available to authorized users.

Hanna Maria Baranowska

hanna.baranowska@up.poznan.pl

1 Institute of Food Technology of Plant Origin, Poznań University of Life Sciences, Poznań, Poland

2 Department of Physics and Biophysics, Poznań University of Life Sciences, Poznań, Poland

3 Students' Scientific Club of Food Technologists, Poznań University of Life Sciences, Poznań, Poland

4 Institute of Chemistry and Technical Electrochemistry, Poznan University of Technology, Poznań, Poland

5 Department of Genetics and Plant Breeding, Poznań University of Life Sciences, Poznań, Poland appropriate additives for bread production. Most studies focus on explaining the interaction of bread ingredients with the additives used, as well as on their activity after the digestion process [1-3]. It is worth remembering, however, that the use of unconventional additives may significantly change the physicochemical characteristics of the bread obtained, including the texture or water properties [4-6].

Fruits like raspberries and strawberries are small have fleshy consistency. These fruits are so popular in Europe and all over the world because of the taste. Raspberries and strawberries are perceived by consumers as healthy due to the rich composition of vitamins and minerals contained in them. They contain minerals such as: $\mathrm{Cu}, \mathrm{I}, \mathrm{Fe}, \mathrm{Mg}, \mathrm{K}$ and $\mathrm{Mn}$ and vitamins (K, C and B), folic acid, fatty acids, polyphenols [7].

Strawberries are a good source of antioxidants like polyphenolic, such as anthocyanins [8]. The total content of anthocyanins is $150-600 \mathrm{mg} / \mathrm{kg}$ of fresh weight [9]. Strawberries also contain proanthocyanidins, which may have antifungal properties [10]. Strawberry seeds constitute $1 \%$ of fruit, however, their content in the fruit depends on its species $[11,12]$. In recent years, scientists have become interested in new, unconventional sources of plant oil. Strawberry 
seeds are one of the most interesting raw materials. After the pressing process, the oilcake, which is a production waste, is almost completely defatted [13]. Unlike strawberries, the content of seeds in raspberries is definitely higher. Also these fruits are great for human health because they contain antioxidant ingredients $[8,14,15]$. These are compounds that inhibit oxidation processes in small concentrations. To the main antioxidants compounds belong polyphenolic compounds that include phenolic acids, flavanols, anthocyanins, proanthocyanidins and ellagitannins. Total value of these ingredients is more than $200 \mathrm{mg}$ per $100 \mathrm{~g}[16,17]$. The main value ingredients of raspberries are carbohydrates, they are $50-80 \%$ of total dry weight. Raspberries contain such sugars as: disaccharide sucrose fructose and monosaccharides glucose. The amount of sugars increases with increasing fruit maturity [18]. Raspberry seeds constitute 9-12\% of the fruit weight and are a by-product formed mainly in the production of wine and juices. Due to the high recovery rate of oil, in the range of 10-23\%, they are also increasingly used for the production of cold-pressed oil used more and more widely in cosmetics [19].

Processing of raspberries and strawberries into juices and purees usually removes seeds as a by-product [20]. The use of waste seeds as a food additive for bread production on the one hand will allow to develop the growing amount of waste, on the other hand it will allow to obtain new, previously unused food stuff with interesting nutritional values [21, 22]. According to Korus et al. [23], after the oil pressing process, almost completely fat-free oilcake was obtained, which can be used as a functional additive for the production of glutenfree bread. In addition, the use of by-products both after oil extraction as well as from fruit and vegetable processing can reduce the amount of waste generated [24]. Therefore, the aim of this work was to evaluate the effect of wheat flour replacement with raspberry or strawberry oilcake on nutritional value, crumb texture, water activity and dynamics of breads supplemented with them.

\section{Materials and methods}

\section{Materials}

Oilcakes from raspberries (Rubus idaeus L.) and strawberries (Fragaria grandiflora L.) were obtained, as by-products, by room-temperature pressing of berry seeds using a Farmet Uno cold-pressing machine (Farmet, Česká Skalice, Czech Republic) and were denoted in the text as ROC and SOC, respectively. The temperature of the heating sleeve in the press was $60 \pm 10^{\circ} \mathrm{C}$, and the temperature of the oils, as well as oilcakes were $39 \pm 1{ }^{\circ} \mathrm{C}$ [25]. After cooling, oilcakes were milled using a M 20 Universal mill (IKA ${ }^{\circledR}$-Werke GmbH \& CO. KG, Staufen, Germany) and then sieved through a
$0.5 \mathrm{~mm}$ sieve using vibratory sieve shaker AS 200 basic (Retsch GmbH \& Co. KG, Haan, Germany). Wheat flour (type 650) was purchased from GoodMills Polska sp. z o.o. (Grodzisk Wielkopolski, Poland), compressed baker's yeast from Lesaffre (Poland) and salt from Kopalnia Soli 'Kłodawa' S.A. (Poland). All other reagents were of analytical grade.

\section{Dough preparation and baking}

The recipe for reference bread (denoted as $\mathrm{C}$ in the text) was as follows: $500 \mathrm{~g}$ wheat flour, $15 \mathrm{~g}$ yeast, $7.5 \mathrm{~g}$ salt and $300 \mathrm{~mL}$ water. In the test samples wheat flour was replaced with powdered raspberries and strawberries oilcakes in three different quantities of 5\%,10\% and 15\%; the amounts of other components were unchanged. The samples were named B5R, B10R, B15R for raspberry oilcake and B5S, B 10S and B15S for strawberry oilcake. Dough was prepared using a straight dough method. All the compounds were mixed together with the KitchenAid (model 5KPM5EWH, KitchenAid, USA) mixer for $10 \mathrm{~min}$ at a speed of $70 \mathrm{rpm}$. Next, the dough was fermented in the fermentation chamber for $60 \mathrm{~min}$ (temperature $35^{\circ} \mathrm{C}$, relative humidity $85 \%$ ), punched, then the dough was divided into pieces of equal weight (350 g), hand-moulded, proofed for $20 \mathrm{~min}$, and baked at $230{ }^{\circ} \mathrm{C}$ for $30 \mathrm{~min}$ (MIWE Michael Wenz GmbH, Amstein, Germany). Afterwards the obtained breads were left at room temperature for $2 \mathrm{~h}$ to cool down, weighed and packed in polypropylene pouches.

\section{Proximate composition}

The total nitrogen was determined, by Kjeldahl method, according to ISO 20483 [26] and was used to calculate the protein content $(\mathrm{P})$ by multiplying the result by the conversion factor of 5.7. The ash content was determined according to ISO 2171 [27] and the total fat content (F) was determined according to AACC 30-25.01 [28]. The content of dietary fibre (DF) was determined by the enzymatic method in accordance to the AOAC official method 994.13 [29]. Measurement of moisture content measurement was performed according to AACCI 44-19.01 [30]. The proximate carbohydrate content (C) was estimated by subtracting the total ash, fat, fibre, protein and moisture content from $100 \%$. Moreover, the energy value (EV) was calculated with the following formula [31]:

$\mathrm{EV}[\mathrm{kcal} / 100 \mathrm{~g}]=4 \times(\mathrm{P}+\mathrm{C})+9 \times \mathrm{F}+2 \times \mathrm{DF}$.

\section{Colour measurements}

The colour of the crumb was measured using a Chroma Meter CR-410 (Konica Minolta Sensing Inc., Tokyo, Japan) 
[32]. Differences in colour were recorded in CIE $L^{*} a^{*} b^{*}$ scale in terms of lightness $\left(L^{*}\right)$ and colour ( $a^{*}$-redness; $b^{*}$-yellowness). Colour measurement was repeated 15 times for each sample. Additionally, the total colour difference $(\Delta E)$ was calculated using the following formula [33]:

$\Delta E=\sqrt{\Delta L^{* 2}+\Delta a^{* 2}+\Delta b^{* 2}}$.

\section{Texture analysis}

Texture profile analysis of bread was performed with a TA.XTplus model texture analyser (Stable Micro System Co. Ltd., Surrey, England) equipped with a 5-kg load cell was used [34]. Each sample was compressed twice with a cylindrical plunger probe of a $35 \mathrm{~mm}$ diameter. The instrument test parameters were set as following: pre-test speed: $7.0 \mathrm{~mm} / \mathrm{s}$; test speed: $5.0 \mathrm{~mm} / \mathrm{s}$; post-test speed: $5.0 \mathrm{~mm} / \mathrm{s}$; strain $40 \%$. Bread loaves were cut into slices $(25 \mathrm{~mm}$ thick each and ends were discarded), and so used to evaluate hardness, springiness, cohesiveness, chewiness and resilience. Texture analysis was repeated 10 times for each sample.

\section{Measurements of water activity}

The changes of the water activity $a_{\mathrm{w}}$ in the bread crumbs were conducted using a water diffusion and activity analyser ADA-7 (COBRABID, Poznań, Poland) with automatic recording of water evacuation from individual samples [35]. The amount of the sample was set at $5 \mathrm{~mm}$ and then placed in the measurement chamber. Before the analysis, the temperature was stabilized at $21.0 \pm 0.1{ }^{\circ} \mathrm{C}$ using the Peltier modules, and then dried to the activity of $0.1000 \pm 0.0005$. Duration of one measurement was set to $1200 \mathrm{~s}$. Water activity measurements were used to describe water transport in breads, employing following phenomenological model [36]:

$a_{\mathrm{w}}(t)=a_{\mathrm{r}}+\left(a_{0}-a_{\mathrm{p}}\right) \mathrm{e}^{-V_{\mathrm{D}} t}+\left(a_{\mathrm{p}}-a_{\mathrm{r}}\right) \mathrm{e}^{-V_{\mathrm{p}} t}$,

where $a_{\mathrm{w}}(t)$ is the temporary water activity value, $a_{0}$ is the initial water activity, $a_{\mathrm{p}}$ is the limit water activity (intermediate), $a_{\mathrm{r}}$ is the water activity at equilibrium condition (final), $V_{\mathrm{D}}$ is the transport rate, and $V_{\mathrm{p}}$ is the rate of the surface conduction.

\section{NMR measurement}

The NMR measurements were determined according to Baranowska's method [37]. The crumb samples of $1.5 \mathrm{~cm}^{3}$ were placed in measuring tt tubes and sealed using Parafilm ${ }^{\circledR}$. Measurements of the spin-lattice $\left(T_{1}\right)$ and spin-spin $\left(T_{2}\right)$ relaxation times were performed using a pulse NMR spectrometer MSL30 operating at $30 \mathrm{MHz}$ (WL Electronics, Poland). The crumbs were measured at $21.0 \pm 0.5^{\circ} \mathrm{C}$. The inversion-recovery (180-t-90) [38] pulse sequence was applied for measurements of the $T_{1}$ relaxation times. Distances between RF pulses $(t)$ were changed within the range from 20 to $80 \mathrm{~ms}$ and the repetition time was from $10 \mathrm{~s}$. Each time, 32 FID signals and 119 points from each FID signal were collected. Calculations of the spin-lattice relaxation time values were performed with the assistance of the CracSpin program. The program for calculating relaxation parameters from experimental data uses 'spin grouping' approach. Marquardt's method of minimization has been applied for fitting multiexponential decays. The accuracy of the relaxation parameters has been estimated with the standard deviation. Time changes of the current value of the FID signal amplitude in the employed frequency of impulses are described by the following formula:

$M_{\mathrm{z}}(t)=M_{0}\left\{1-2 \exp \left(\frac{-t}{T_{1}}\right)\right\}$,

where $M_{\mathrm{z}}(t)$ is the actual magnetization value, and $M_{0}$ is the equilibrium magnetization value.

A monoexponentially magnetization recovery was found, which means that the system relaxes with one $T_{1}$ spin-lattice relaxation time.

Measurements of the spin-spin $\left(T_{2}\right)$ relaxation times were taken using the pulse train of the Carr-Purcell-Meiboom-Gill spin echoes [90-t/2-(180) $]$ [38]. The distance ( $t$ ) between 180 RF pulses amounted from 0.5 to $0.8 \mathrm{~ms}$. The repetition time was $10 \mathrm{~s}$. The number of spin echoes $(n)$ amounted to 100 . Five accumulation signals were employed. To calculate the spin-spin relaxation time values, the authors applied the adjustment of values of the echo amplitudes to the formula [39]:

$M_{x, y}(t)=M_{0} \sum_{i=1}^{n} p_{i} \exp \left[\frac{-t}{T_{2 i}}\right]$,

where $M_{x, y}(t)$ is the echo amplitude, $M_{0}$ is the equilibrium amplitude, $p_{i}$ is the fraction of protons relaxing with the $T_{2 i}$ spin-spin time.

The calculations were performed by using the dedicated software by application of non-linear least-square algorithm. The accuracy of the relaxation parameters was estimated with the standard deviation. The presence of two proton fractions was determined for all analysed systems.

\section{Statistical analysis}

For every test tree independent repeated measurements were done, unless stated otherwise. All measurements were studied using one-way analysis of variance independently for each dependent variable. A post hoc Tukey HSD (honest significant difference) multiple comparison tests were used to identify statistically homogeneous subsets at $\alpha=0.05$. 
Principal component analysis (PCA) was performed using selected data obtained in the analyses. The result is presented in a two-dimensional system (biplot) obtained by plotting the observations and variables on the plane formed by the calculated principal components. Additionally, a correlation matrix was constructed for the variables used in PCA. Statistical analysis of the data was performed with Statistica 13 (Dell Software Inc., USA) software.

\section{Results and discussion}

\section{Proximate composition and colour}

Fruit pomace is a rich source of nutrients such as sugars, organic acids, protein, dietary fibre, as well as polyphenols and tocopherols, so they can be a good addition to the bread to increase its nutritional value [40]. In the present study, oilcakes obtained after the oil pressing process were used. ROC and SOC were characterized for the content of the most important macronutrients. The moisture content was $7.47 \pm 0.04 \%$ for ROC and $7.08 \pm 0.03 \%$ for SOC; protein content $14.2 \pm 1.21 \%$ and $18.4 \pm 1.33 \%$; ash content $2.14 \pm 0.02 \%$ and $3.21 \pm 0.04 \%$, dietary fibre $69.11 \pm 1.37 \%$ and $65.25 \pm 1.71 \%$, respectively. The results showed that the oilcakes are a good source of dietary fibre and are consistent with the literature data. According to Kosmala et al. [41], defatted strawberry seeds contain more protein than the raspberry seed oilcake. They also proved that the total dietary fibre content was $74 \%$ in the case of raspberry oilcake and $69 \%$ in the case of strawberry oilcake, including soluble dietary fibre, respectively: $6.1 \%$ and $1.4 \%$. The effect of flour substation with ROC and SOC on nutritional value of obtained bread, understood as the content of protein, fat, ash and carbohydrates, was analysed. The results are presented in Table 1. It has been shown that the addition of SOC significantly increases the protein content in the bread by $12.23 \%$ for $\mathrm{B} 15 \mathrm{~S}$ compared to $\mathrm{C}$. The addition of ROC also caused an increase in protein content, but at a much lower level (by $3.77 \%$, respectively). The addition of ROC and SOC influenced the increase of fat content in the analysed bread, which ranged from 1.32 to $2.14 \%$ for B5R and B15R, and from 1.30 to $2.08 \%$ for B5S and B15S. An increase in ash and dietary fibre contents was also observed. According to the assumptions, the content of dietary fibre in enriched breads increased significantly, from $1.88 \%$ for C, to $7.36 \%$ for B15R and $7.90 \%$ for B15S. Food can be considered as 'rich' in fibre if it contains at least $6 \mathrm{~g} / 100 \mathrm{~g}$ or $3 \mathrm{~g} / 100 \mathrm{kcal}$. Most European countries recommend daily intake of fibre in the amount of 25-35 g for adults (25-32 g/ day for adult women and 30-35 g/day for adult men) and less for children and elder people [42]. Consuming an adequate amount of dietary fibre has documented health benefits, e.g. $10 \mathrm{~g}$ of fibre daily reduces the overall mortality caused by various diseases by $11 \%$ [43], moreover for total dietary fibre intake indicate a reduction in cardiovascular disease events between 7 and $9 \%$ for each $7 \mathrm{~g}$ daily increment consumed $[44,45]$. The consequence of changes in individual nutrients is the reduction of carbohydrates from 82.9 to $75.6 \%$ for B15R and $73.9 \%$ for B15S. Carbohydrates are particularly important in cereals, which usually contain about $50-80 \%$ carbohydrates on a dry basis, among which starch is the most common cereal polysaccharide and is the main reserve of food providing mass nutrients and energy in the human diet [46]. Differences in the content of macronutrients, however, did not affect the energy value of the obtained bread, which were similar to those described in the literature [47-49].

The consumers' acceptance of food is based not only on the assessment of nutritional value, but also on sensory properties. An important parameter that directly affects
Table 1 Proximate composition of breads with oilcakes

\begin{tabular}{lcccccc}
\hline Sample & Protein $(\mathrm{g} / 100 \mathrm{~g})$ & Fat $(\mathrm{g} / 100 \mathrm{~g})$ & Ash $(\mathrm{g} / 100 \mathrm{~g})$ & Fibre $(\mathrm{g} / 100)$ & $\begin{array}{l}\text { Carbo- } \\
\text { hydrates } \\
(\mathrm{g} / 100 \mathrm{~g})\end{array}$ & $\begin{array}{l}\text { Energy value }^{\mathrm{b}} \\
(\mathrm{kcal} / 100 \mathrm{~g})\end{array}$ \\
\hline $\mathrm{C}$ & $13.25 \pm 0.02^{\mathrm{e}}$ & $1.10 \pm 0.04^{\mathrm{d}}$ & $0.84 \pm 0.04^{\mathrm{c}}$ & $1.88 \pm 0.17^{\mathrm{d}}$ & $82.9 \pm 1.1^{\mathrm{a}}$ & 225.0 \\
$\mathrm{~B} 5 \mathrm{R}$ & $13.29 \pm 0.18^{\mathrm{e}}$ & $1.32 \pm 0.02^{\mathrm{c}}$ & $0.88 \pm 0.07^{\mathrm{c}}$ & $3.88 \pm 1.01^{\mathrm{c}}$ & $80.6 \pm 1.0^{\mathrm{a}}$ & 221.7 \\
$\mathrm{~B} 10 \mathrm{R}$ & $13.59 \pm 0.06^{\mathrm{c}}$ & $1.73 \pm 0.02^{\mathrm{b}}$ & $1.02 \pm 0.06^{\mathrm{b}}$ & $5.89 \pm 1.07^{\mathrm{b}}$ & $77.8 \pm 1.0^{\mathrm{b}}$ & 221.3 \\
$\mathrm{~B} 15 \mathrm{R}$ & $13.75 \pm 0.11^{\mathrm{c}}$ & $2.14 \pm 0.05^{\mathrm{a}}$ & $1.07 \pm 0.05^{\mathrm{b}}$ & $7.36 \pm 1.23^{\mathrm{a}}$ & $75.6 \pm 0.9^{\mathrm{bc}}$ & 220.0 \\
$\mathrm{~B} 5 \mathrm{~S}$ & $13.45 \pm 0.02^{\mathrm{de}}$ & $1.30 \pm 0.04^{\mathrm{c}}$ & $0.91 \pm 0.04^{\mathrm{c}}$ & $3.71 \pm 0.98^{\mathrm{c}}$ & $80.6 \pm 1.0^{\mathrm{a}}$ & 224.9 \\
$\mathrm{~B} 10 \mathrm{~S}$ & $14.14 \pm 0.11^{\mathrm{b}}$ & $1.79 \pm 0.08^{\mathrm{b}}$ & $1.25 \pm 0.05^{\mathrm{a}}$ & $5.53 \pm 1.04^{\mathrm{b}}$ & $77.3 \pm 0.9^{\mathrm{b}}$ & 223.4 \\
$\mathrm{~B} 15 \mathrm{~S}$ & $14.87 \pm 0.17^{\mathrm{a}}$ & $2.08 \pm 0.03^{\mathrm{a}}$ & $1.27 \pm 0.04^{\mathrm{a}}$ & $7.90 \pm 1.15^{\mathrm{a}}$ & $73.9 \pm 0.8^{\mathrm{c}}$ & 219.6 \\
\hline
\end{tabular}

Mean values with different letters ( $\mathrm{a}-\mathrm{d}$ ) in the columns are significantly different at $\alpha=0.05$

C-reference bread; B5R, B10R, B15R-breads with 5\%, 10\% and 15\% raspberry oilcake, respectively; B5S, B10S, B15S - breads with 5\%,10\% and 15\% strawberry oilcake, respectively

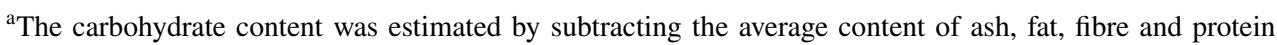
from $100 \%$

${ }^{\mathrm{b}}$ Energy value was calculated based on average moisture, protein, fat, fibre and carbohydrate content 
consumer choice is its colour [50]. The CIE $L^{*} a^{*} b^{*}$ parameters corresponded, respectively, to the lightness of the samples, the saturation of the red and the saturation of the yellow [51]. The results of the colorimetric colour analysis showed that the value of the $L^{*}$ parameter was reduced, in relation to $\mathrm{C}$, by approx. $30 \%$ for B15R and about $35 \%$ for B15S, which means obtaining a darker crumb compared to the sample without addition (Table 2). Also in the work published by Koca and Anil [52] a significant reduction in lightness was noted due to the addition of flaxseed. In addition, a significant increase in red saturation of the analysed samples was observed, which may be related to the content of anthocyanins in oilcake containing fruits containing them [40]. Similar results were obtained in the work of Korus et al. [23], where strawberry seeds were added to the bread. The yellow colour saturation in the analysed samples decreased compared to $\mathrm{C}$ (18.09) and ranged from 13.22 for B15S to 10.57 for B15R. The calculated total colour difference $(\Delta E)$, for individual test samples relative to the control, showed that the colour changes ranged from 16.87 to 23.99 for the ROC addition, and from 18.43 to 27.14 for the SOC addition. The colour difference greater than $3(\Delta E>3)$ is

Table 2 The results of colour analyses

\begin{tabular}{llrll}
\hline Sample & \multicolumn{1}{l}{$L^{*}$} & \multicolumn{1}{l}{$a^{*}$} & \multicolumn{1}{l}{$b^{*}$} \\
\hline C & $67.95 \pm 0.67^{\mathrm{a}}$ & $1.11 \pm 0.06^{\mathrm{e}}$ & $18.09 \pm 0.19^{\mathrm{a}}$ & - \\
B5R & $54.11 \pm 0.58^{\mathrm{b}}$ & $10.09 \pm 0.10^{\mathrm{b}}$ & $14.59 \pm 0.21^{\mathrm{b}}$ & 16.87 \\
B10R & $49.48 \pm 0.57^{\mathrm{d}}$ & $11.22 \pm 0.24^{\mathrm{a}}$ & $14.08 \pm 0.28^{\mathrm{b}}$ & 21.62 \\
B15R & $46.84 \pm 0.39^{\mathrm{e}}$ & $11.78 \pm 0.22^{\mathrm{a}}$ & $13.22 \pm 1.04^{\mathrm{bc}}$ & 23.99 \\
B5S & $52.05 \pm 0.67^{\mathrm{c}}$ & $8.39 \pm 0.06^{\mathrm{d}}$ & $12.28 \pm 0.19^{\mathrm{c}}$ & 18.43 \\
B10S & $47.21 \pm 0.54^{\mathrm{e}}$ & $9.04 \pm 0.10^{\mathrm{c}}$ & $11.68 \pm 0.11^{\mathrm{d}}$ & 23.12 \\
B15S & $43.22 \pm 0.69^{\mathrm{f}}$ & $9.36 \pm 0.15^{\mathrm{c}}$ & $10.57 \pm 0.38^{\mathrm{e}}$ & 27.14 \\
\hline
\end{tabular}

Mean values with different letters (a-f) in the columns are significantly different at $\alpha=0.05$

C-reference bread; B5R, B10R, B15R-breads with 5\%, 10\% and $15 \%$ raspberry oilcake, respectively; B5S, B10S, B15S-breads with $5 \%, 10 \%$ and $15 \%$ strawberry oilcake, respectively so significant that it can be observed with the naked eye even by a non-trained assessor [53].

\section{Textural properties}

Differences in the proportions of macronutrients were reflected in the results of the TPA test, which were presented in Table 3. Analysis showed a clear influence of the used oilcakes on the textural properties of the obtained bread. Both the addition of ROC and SOC significantly increased the hardness by $62 \%$ for B 15 S and $94 \%$ for B $15 R$ compared to C. According to Kosmala et al. [41], ROC and SOC are raw materials containing significant amounts of dietary fibre and protein as well, which increased the content of these macronutrients in the obtained bread in our study, and consequently contributed to the increase of hardness of the crumb. ROC contains in its composition more fibre and protein, which directly affected the higher hardness of bread with ROC compared to SOC. However, no effect of 5\% flour replacement on crumb hardness was observed. The increase in hardness of the crumb due to the replacement of wheat flour with raw materials containing fibre and protein is also confirmed by published data [6, 54]. In addition, published data indicates that changes in the recipe can cause the formation of not only harder but also less elastic crumbs [5, 55], which has also been demonstrated in these studies. The analysed breads showed, however, decreased elasticity indicated by the observed values of springiness and resilience. The springiness value of all analysed breads, except for B5S, decreased statistically significantly. Crumb chewiness reflects the energy required to masticate food to a ready-to-swallow state. This parameter derived from firmness, cohesiveness and springiness [56]. This parameter also significantly increases due to the use of oilcake from 1133 for $\mathrm{C}$ to even 2090 for B15R.
Table 3 Texture profile analysis results

\begin{tabular}{llllll}
\hline Sample & Hardness $(N)$ & Springiness $(\%)$ & Cohesiveness $(-)$ & Chewiness $(-)$ & Resilience $(-)$ \\
\hline C & $14.56 \pm 1.43^{\mathrm{c}}$ & $97.2 \pm 1.0^{\mathrm{a}}$ & $0.798 \pm 0.031^{\mathrm{a}}$ & $1133 \pm 95^{\mathrm{c}}$ & $0.441 \pm 0.025^{\mathrm{a}}$ \\
B5R & $14.82 \pm 2.29^{\mathrm{c}}$ & $95.2 \pm 0.7^{\mathrm{b}}$ & $0.783 \pm 0.025^{\mathrm{a}}$ & $1149 \pm 139^{\mathrm{c}}$ & $0.423 \pm 0.022^{\mathrm{a}}$ \\
B10R & $20.67 \pm 2.40^{\mathrm{bc}}$ & $95.1 \pm 0.6^{\mathrm{b}}$ & $0.766 \pm 0.043^{\mathrm{a}}$ & $1525 \pm 193^{\mathrm{ab}}$ & $0.395 \pm 0.032^{\mathrm{b}}$ \\
B15R & $28.28 \pm 2.17^{\mathrm{a}}$ & $94.9 \pm 1.1^{\mathrm{b}}$ & $0.768 \pm 0.056^{\mathrm{a}}$ & $2090 \pm 144^{\mathrm{a}}$ & $0.394 \pm 0.032^{\mathrm{b}}$ \\
B5S & $15.81 \pm 2.26^{\mathrm{c}}$ & $96.1 \pm 0.7^{\mathrm{a}}$ & $0.786 \pm 0.040^{\mathrm{a}}$ & $1211 \pm 118^{\mathrm{bc}}$ & $0.422 \pm 0.030^{\mathrm{a}}$ \\
B10S & $20.14 \pm 2.21^{\mathrm{bc}}$ & $95.9 \pm 0.4^{\mathrm{b}}$ & $0.764 \pm 0.045^{\mathrm{a}}$ & $1494 \pm 127^{\mathrm{b}}$ & $0.398 \pm 0.034^{\mathrm{b}}$ \\
B15S & $23.61 \pm 1.11^{\mathrm{b}}$ & $95.6 \pm 0.3^{\mathrm{b}}$ & $0.750 \pm 0.044^{\mathrm{a}}$ & $1717 \pm 189^{\mathrm{a}}$ & $0.395 \pm 0.027^{\mathrm{b}}$ \\
\hline
\end{tabular}

Mean values with different letters (a-f) in the columns are significantly different at $\alpha=0.05$

C-reference bread; B5R, B10R, B15R-breads with 5\%, 10\% and 15\% raspberry oilcake, respectively; B5S, B10S, B15S—breads with 5\%, 10\% and 15\% strawberry oilcake, respectively 


\section{Water behaviour}

Literature data suggest that changes at the molecular level that change the dynamics of water affect the texture of the product [57], thus the molecular properties of water were analysed in the tested samples. In the bread crumb the fraction of mobile water and the water fraction with inhibited dynamics could be observed [58]. The chemical exchange between the molecules of the bulk and bound water of the mobile fraction takes place quickly, hence the analysed systems are characterized by one relaxation time spin-lattice $T_{1}$ (Table 4). The higher the value of $T_{1}$ the more is mobile water molecules in the analysed system, compared to the water directly associated with the large molecules of biopolymers. It was found that the relaxation time values spin-lattice $T_{1}$ decrease with the increase of wheat flour replacement with the oilcakes, therefore the oilcake is a water absorber. The crumb of bread with the addition of ROC is characterized by a larger amount of bound water fraction compared to the bulk water fraction, than the crumb of bread with the addition of SOC, which explains the differences in hardness. Water participates in the creation of the polymer network structure in bread. The fewer molecules of water trapped in the network-bound water fraction-the less hardness and greater springiness. However, the addition of SOC slightly more inhibits the mobility of bulk water molecules, which is manifested by the smaller values of $T_{22}$ spin-spin relaxation times recorded for individual sample variants. This is related to the presence of a large amount of protein, the content of which determines mobility mainly the bulk fraction. The more protein, the less possible the rotational movements of water molecules. In comparison to the control crumb, those with the addition of $5 \%$ or $10 \%$ of the oilcakes are characterized by very small values of $T_{21}$ - the component of the relaxation time describing the molecular dynamics of bound water fraction. The mobility of free water is limited by the formation of ionic and hydrogen bonds between water molecules and macromolecules, for example protein [59], thus the higher content in tested breads of this ingredient could affect the changes observed. The decrease in the $T_{22}$ value suggests a significant change in the dynamics of the free water fraction. It can therefore be concluded that this bread not only contains the lowest amount of free water, but this fraction has also the most limited molecular dynamics. The empirical model of activity and diffusion of water in the biopolymer structure was used [36] to analyse the diffusion rate of water in the tested samples. It was noticed that the oilcakes of both types (from raspberry and strawberry seeds) limit the rate of diffusion of water molecules in the interior of the crumb. It has been found that as the amount of the oilcake increases, the diffusion rate increases. The addition of $5 \%$ and $10 \%$ of oilcake reduces the evacuation of water from the sample surface compared to the control sample.

LF NMR measurements, diffusion and water activity are related to studies of molecular water properties, and the results complement macroscopic studies. A correlation was found between the water diffusion rate in bread $\left(V_{\mathrm{D}}\right)$ and spin-lattice relaxation time $T_{1}$ (Fig. 1a), as well as long components of spin-spin relaxation times $T_{22}$ (Fig. 1b). The translational movement of water molecules is inhibited by the immobilization of unbound water, which manifests itself in inversely proportional dependence $V_{\mathrm{D}}=f\left(T_{22}\right)$. The rate of evacuation of water from the surface of the test $\left(V_{\mathrm{p}}\right)$ increases as the mobility of molecules of water bound increases (Fig. 1c). The presented work attempts to correlate parameters analysed by two independent methods describing various aspects of the dynamic properties of water in bread. LF NMR reflects the rotational dynamics of water, while the model of activity and diffusion allows the analysis of the translational properties of water molecules. It is well known that the values of relaxation times are correlated with the water content and the manner of its binding. However, the novel approach to the molecular properties of water in the
Table 4 The results of ${ }^{1} \mathrm{H}$ NMR analysis and water activity

\begin{tabular}{llllll}
\hline Sample & \multicolumn{1}{l}{$T_{1}(\mathrm{~ms})$} & $T_{21}(\mathrm{~ms})$ & \multicolumn{1}{l}{$T_{22}(\mathrm{~ms})$} & $a_{\mathrm{p}}(-)$ & $a_{\mathrm{r}}(-)$ \\
\hline C & $111.34 \pm 0.57^{\mathrm{a}}$ & $0.84 \pm 0.07^{\mathrm{c}}$ & $11.00 \pm 0.21^{\mathrm{a}}$ & $0.5606 \pm 0.0002^{\mathrm{a}}$ & $0.8961 \pm 0.0004^{\mathrm{b}}$ \\
B5R & $73.18 \pm 0.30^{\mathrm{c}}$ & $0.23 \pm 0.02^{\mathrm{f}}$ & $8.17 \pm 0.15^{\mathrm{b}}$ & $0.3402 \pm 0.0003^{\mathrm{g}}$ & $0.8938 \pm 0.0002^{\mathrm{d}}$ \\
B10R & $55.13 \pm 0.49^{\mathrm{f}}$ & $0.40 \pm 0.04^{\mathrm{d}}$ & $7.36 \pm 0.31^{\mathrm{c}}$ & $0.3868 \pm 0.0004^{\mathrm{f}}$ & $0.8941 \pm 0.0005^{\mathrm{c}}$ \\
B15R & $45.76 \pm 0.21^{\mathrm{g}}$ & $0.98 \pm 0.02^{\mathrm{b}}$ & $5.99 \pm 0.44^{\mathrm{d}}$ & $0.4944 \pm 0.0005^{\mathrm{c}}$ & $0.8991 \pm 0.0002^{\mathrm{a}}$ \\
B5S & $81.07 \pm 0.42^{\mathrm{b}}$ & $0.27 \pm 0.02^{\mathrm{e}}$ & $7.50 \pm 0.17^{\mathrm{c}}$ & $0.4603 \pm 0.0004^{\mathrm{e}}$ & $0.8889 \pm 0.0002^{\mathrm{e}}$ \\
B10S & $69.01 \pm 0.32^{\mathrm{d}}$ & $0.44 \pm 0.02^{\mathrm{d}}$ & $6.44 \pm 0.21^{\mathrm{d}}$ & $0.4801 \pm 0.0002^{\mathrm{d}}$ & $0.8891 \pm 0.0003^{\mathrm{e}}$ \\
B15S & $58.31 \pm 0.32^{\mathrm{e}}$ & $1.07 \pm 0.04^{\mathrm{a}}$ & $5.74 \pm 0.35^{\mathrm{e}}$ & $0.5429 \pm 0.0003^{\mathrm{b}}$ & $0.8968 \pm 0.0004^{\mathrm{b}}$ \\
\hline
\end{tabular}

Mean values with different letters ( $\mathrm{a}-\mathrm{g}$ ) in the columns are significantly different at $\alpha=0.05$

C-reference bread; B5R, B10R, B15R-breads with 5\%, 10\% and 15\% raspberry oilcake, respectively; B5S, B10S, B15S - breads with 5\%, 10\% and 15\% strawberry oilcake, respectively; $a_{\mathrm{p}}$-limit water activity (intermediate); $a_{\mathrm{r}}$-water activity at equilibrium condition (final) 

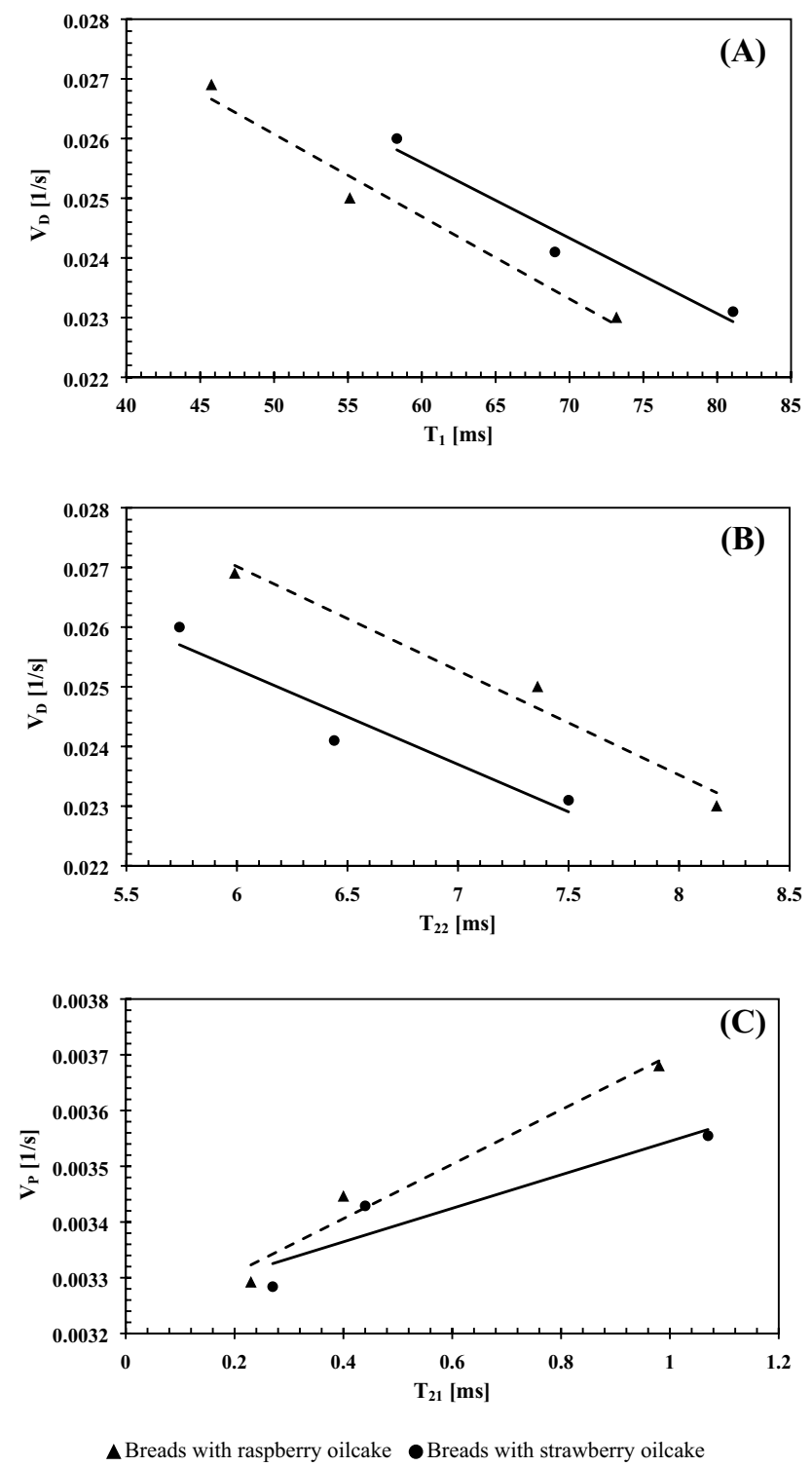

Fig. $1 \mathrm{~V}_{\mathrm{D}}$ parameter changes as a function of $T_{1}(\mathbf{a}) ; V_{\mathrm{D}}$ parameter changes as a function of $T_{22}(\mathbf{b}) ; V_{\mathrm{p}}$ parameter changes as a function of $T_{21}(\mathbf{c})$

studied system, which is not widely used, gives the possibility of a wider analysis than the relationships described so far between LF NMR results and water activity.

Principal component analysis of the two texture parameters (hardness, springiness), NMR relaxometry results $\left(T_{1}, T_{21}, T_{22}\right)$, equilibrium water activity $\left(a_{\mathrm{r}}\right)$, limit water activity $\left(a_{\mathrm{p}}\right)$ and proximate composition (ash, carbohydrates, fat and protein contents) of the tested samples was performed to analyse the main factors determining the properties of the analysed breads. The two principal components explained $75.99 \%$ of the total variance. The first main component contains $50.35 \%$ of the information about the tested products represented by variables, while the second main component contains $25.64 \%$ of the information. Each of the vectors, shown in Fig. 2a, represents one variable, and its size and direction describes the influence exerted on the main components. Details concerning correlations between the variables are included in Table S1. Projection of the cases on the factor plane (Fig. 2b) indicated the similarity between the breads with the same level of wheat flour replacement with ROC and SOC. At the same time the $\mathrm{C}$ sample differed from the others.

\section{Conclusions}

Wheat bread with ROC and SOC was designed and tested during the reported research. The amount of oilcakes introduced into the recipe influences the proximate composition, colour, texture and water properties of the final product. However, some effects on different responses depending on the botanical origin of oilcakes. Replacing wheat flour with oilseed cakes caused an increase in the content of ash (from $0.84 \mathrm{~g} / 100 \mathrm{~g}$ for $\mathrm{C}$, to 1.07 and $1.27 \mathrm{~g} / 100 \mathrm{~g}$ for B15R and B15S, respectively), fat (1.10, 2.15 and $2.08 \mathrm{~g} / 100 \mathrm{~g}$, respectively) and protein (13.25, 13.75 and $14.87 \mathrm{~g} / 100 \mathrm{~g})$. The increase of total dietary fibre content was also noted [from 1.88 (C) to 7.36 (B15R) and $7.90 \mathrm{~g} / 100 \mathrm{~g}(\mathrm{~B} 15 \mathrm{~S})]$. Generally, the observed changes were more extensive when higher amount of oilcake was introduced, especially in the case of colour and textural properties. The colour of the crumb was shifted towards red and blue, and the lightness decreased. Moreover, the more ROC and SOC entered the recipe, the higher the hardness of the crumb was $(14.56 \mathrm{~N}$ for $\mathrm{C}, 28.28 \mathrm{~N}$ for B15R and 23.61 $\mathrm{N}$ for B15S). The addition of oilcakes influenced also on the molecular dynamics of water in the bread crumb. These changes depend both on the amount of the flour replacement by the oilcake and on the botanical origin of the oilcakes. The obtained results indicate that $15 \%$ substitution of wheat flour by the oilcake result in a significant reduction of the amount of unbound water in the crumb, in relation to bound water, and higher (than in the control sample) rate of water evacuation from the surface. Also the speed of translational diffusion in such samples is comparable to that which is characterized by the crumb of bread without the addition of cakes. Combination of molecular studies on the properties of water with the analysis of macroscopic changes allows for a more complete analysis of enriched food products.

Funding The authors received no financial support for the research, authorship, and/or publication of this article. 
Fig. 2 Projections of the variables (a) and cases (b) on the component plane $(1 \times 2)$
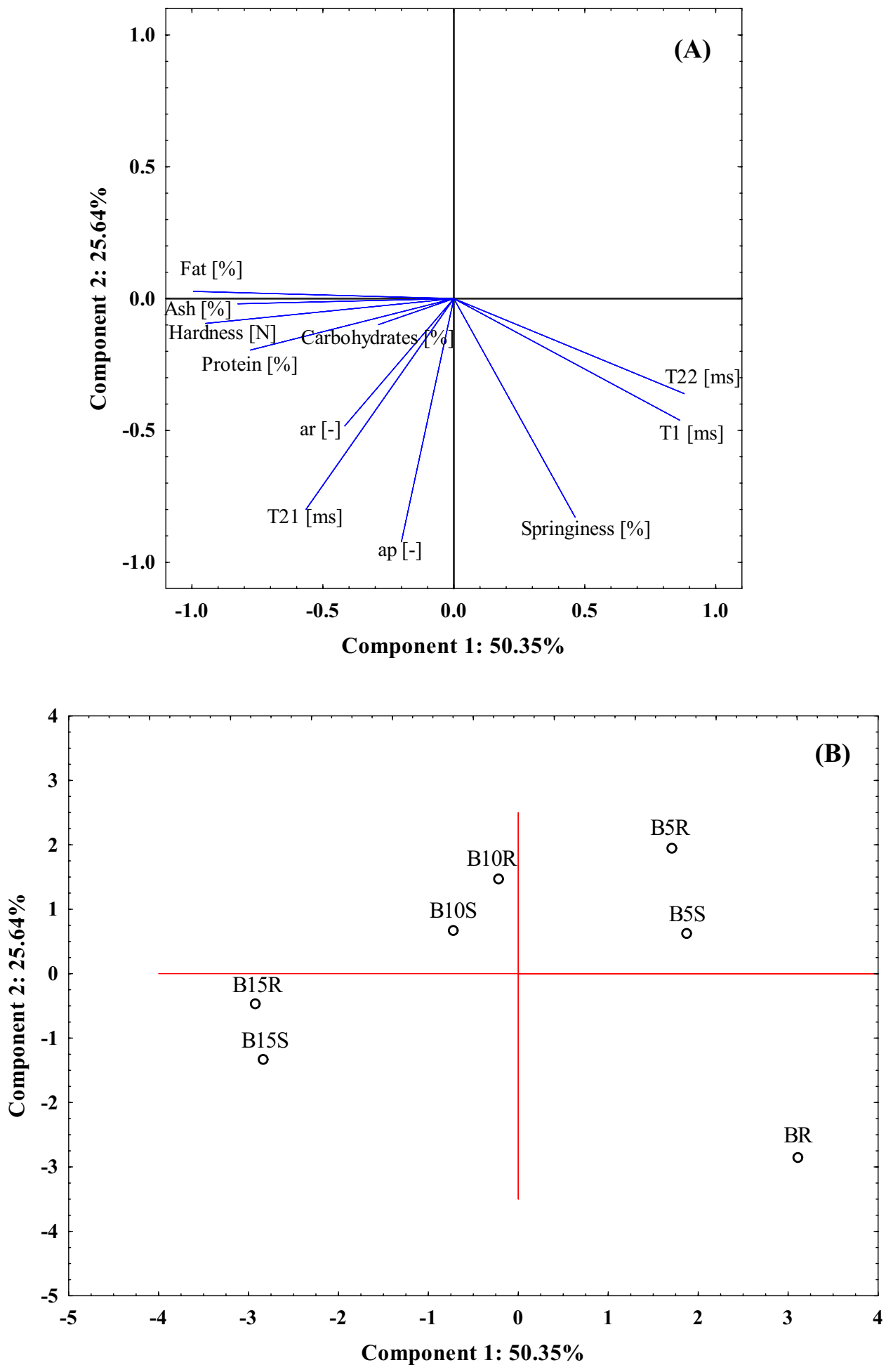

\section{Compliance with ethical standards}

Conflict of interest On behalf of all authors, the corresponding author states that there is no conflict of interest.
Compliance with ethics requirements All procedures followed were in accordance with the ethical standards of the responsible committee on human experimentation (institutional and national). 
Informed consent Informed consent was obtained from all panelist for being included in the study.

Open Access This article is distributed under the terms of the Creative Commons Attribution 4.0 International License (http://creativeco mmons.org/licenses/by/4.0/), which permits unrestricted use, distribution, and reproduction in any medium, provided you give appropriate credit to the original author(s) and the source, provide a link to the Creative Commons license, and indicate if changes were made.

\section{References}

1. Świeca M, Gawlik-Dziki U, Dziki D et al (2013) The influence of protein-flavonoid interactions on protein digestibility in vitro and the antioxidant quality of breads enriched with onion skin. Food Chem 141:451-458. https://doi.org/10.1016/j.foodc hem.2013.03.048

2. Sivam AS, Sun-Waterhouse D, Perera CO, Waterhouse GIN (2012) Exploring the interactions between blackcurrant polyphenols, pectin and wheat biopolymers in model breads; a FTIR and HPLC investigation. Food Chem 131:802-810. https://doi. org/10.1016/j.foodchem.2011.09.047

3. Glei M, Kirmse A, Habermann N et al (2006) Bread enriched with green coffee extract has chemoprotective and antigenotoxic activities in human cells. Nutr Cancer 56:182-192. https://doi. org/10.1207/s15327914nc5602_9

4. Gill S, Vasanthan T, Ooraikul B, Rossnagel B (2002) Wheat bread quality as influenced by the substitution of waxy and regular barley flours in their native and extruded forms. J Cereal Sci 36:219-237. https://doi.org/10.1006/jcrs.2001.0458

5. Ziobro R, Witczak T, Juszczak L, Korus J (2013) Supplementation of gluten-free bread with non-gluten proteins. Effect on dough rheological properties and bread characteristic. Food Hydrocoll 32:213-220. https://doi.org/10.1016/j.foodhyd.2013.01.006

6. Kaack K, Pedersen L, Laerke HN, Meyer A (2006) New potato fibre for improvement of texture and colour of wheat bread. Eur Food Res Technol 224:199-207. https://doi.org/10.1007/s0021 7-006-0301-5

7. Pereira CC, do Nascimento da Silva E, de Souza AO et al (2018) Evaluation of the bioaccessibility of minerals from blackberries, raspberries, blueberries and strawberries. J Food Compos Anal 68:73-78. https://doi.org/10.1016/j.jfca.2016.12.001

8. Wang SY, Lin H-S (2000) Antioxidant activity in fruits and leaves of blackberry, raspberry, and strawberry varies with cultivar and developmental stage. J Agric Food Chem 48:140-146. https://doi. org/10.1021/jf9908345

9. Giampieri F, Tulipani S, Alvarez-Suarez JM et al (2012) The strawberry: composition, nutritional quality, and impact on human health. Nutrition 28:9-19. https://doi.org/10.1016/j. nut.2011.08.009

10. Ayala-Zavala JF, Wang SY, Wang CY, González-Aguilar GA (2004) Effect of storage temperatures on antioxidant capacity and aroma compounds in strawberry fruit. LWT Food Sci Technol 37:687-695. https://doi.org/10.1016/j.1wt.2004.03.002

11. Aaby K, Wrolstad RE, Ekeberg D, Skrede G (2007) Polyphenol composition and antioxidant activity in strawberry purees; impact of achene level and storage. J Agric Food Chem 55:5156-5166. https://doi.org/10.1021/jf070467u

12. Cheel J, Theoduloz C, Rodríguez JA et al (2007) Free radical scavenging activity and phenolic content in achenes and thalamus from Fragaria chiloensis ssp. chiloensis, $F$. vesca and $F$. $\mathrm{x}$ ananassa cv. Chandler. Food Chem 102:36-44. https://doi. org/10.1016/j.foodchem.2006.04.036
13. Rój E, Dobrzyńska-Inger A, Kostrzewa D et al (2009) Extraction of berry seed oils with supercritical $\mathrm{CO}_{2}$. Przem Chem $88: 1325-1330$

14. Beekwilder J, Jonker H, Meesters P et al (2005) Antioxidants in raspberry: on-line analysis links antioxidant activity to a diversity of individual metabolites. J Agric Food Chem 53:3313-3320. https://doi.org/10.1021/jf047880b

15. Mildner-Szkudlarz S, Bajerska J, Górnaś P et al (2016) Physical and bioactive properties of muffins enriched with raspberry and cranberry pomace powder: a promising application of fruit byproducts rich in biocompounds. Plant Foods Hum Nutr 71:165173. https://doi.org/10.1007/s11130-016-0539-4

16. Teng H, Lee WY, Choi YH (2013) Optimization of microwaveassisted extraction for anthocyanins, polyphenols, and antioxidants from raspberry (Rubus Coreanus Miq.) using response surface methodology. J Sep Sci 36:3107-3114. https://doi. org/10.1002/jssc.201300303

17. Hancock RD, Petridis A, McDougall GJ (2018) Raspberry fruit chemistry in relation to fruit quality and human nutrition. Raspberry. Springer International Publishing, Cham, pp 89-119

18. Surya M, Suhartati S, Ismaini L et al (2018) Fruit nutrients of five species of wild raspberries (Rubus spp.) from Indonesian Mountain's forests. J Trop Life Sci 8:75-80. https://doi. org/10.11594/jtls.08.01.13

19. Teng H, Chen L, Huang Q et al (2016) Ultrasonic-assisted extraction of raspberry seed oil and evaluation of its physicochemical properties, fatty acid compositions and antioxidant activities. PLoS One 11:e0153457. https://doi.org/10.1371/ journal.pone. 0153457

20. Brownmiller C, Howard LR, Prior RL (2008) Processing and storage effects on monomeric anthocyanins, percent polymeric color, and antioxidant capacity of processed blueberry products. J Food Sci 73:H72-H79. https://doi.org/10.111 1/j.1750-3841.2008.00761.x

21. Bushman BS, Phillips B, Isbell T et al (2004) Chemical composition of caneberry (Rubus spp.) seeds and oils and their antioxidant potential. J Agric Food Chem 52:7982-7987. https:// doi.org/10.1021/jf049149a

22. Parry J, Yu L (2006) Fatty acid content and antioxidant properties of cold-pressed black raspberry seed oil and meal. J Food Sci 69:FCT189-FCT193. https://doi. org/10.1111/j.1365-2621.2004.tb13356.x

23. Korus J, Juszczak L, Ziobro R et al (2012) Defatted strawberry and blackcurrant seeds as functional ingredients of glutenfree bread. J Texture Stud 43:29-39. https://doi.org/10.111 $1 / \mathrm{j} .1745-4603.2011 .00314 . x$

24. Nawirska A, Kwaśniewska M (2005) Dietary fibre fractions from fruit and vegetable processing waste. Food Chem 91:221225. https://doi.org/10.1016/j.foodchem.2003.10.005

25. Mildner-Szkudlarz S, Różańska M, Siger A et al (2019) Changes in chemical composition and oxidative stability of cold-pressed oils obtained from by-product roasted berry seeds. LWT Food Sci Technol 111:541-547. https://doi.org/10.1016/j. lwt.2019.05.080

26. ISO (2013) ISO 20483:2013 Cereals and pulses-determination of the nitrogen content and calculation of the crude protein content-Kjeldahl method. International Organization for Standardization, Geneva

27. ISO (2007) ISO 2171:2007 Cereals, pulses and by-productsdetermination of ash yield by incineration. International Organization for Standardization, Geneva

28. AACC (2009) AACCI 30-25.01 crude fat in wheat, corn, and soy flour, feeds, and mixed feeds. In: AACC international approved methods. AACC International, Minnesota

29. AOAC (2007) AOAC official method 994.13. Total dietary fiber. AOAC international, Rockville 
30. AACC (2009) AACCI 44-19.01 moisture-air-oven method, drying at 135 degrees. In: AACC international approved methods. AACC International, Minnesota

31. Montowska M, Kowalczewski PŁ, Rybicka I, Fornal E (2019) Nutritional value, protein and peptide composition of edible cricket powders. Food Chem 289:130-138. https://doi. org/10.1016/j.foodchem.2019.03.062

32. Pauter P, Różańska M, Wiza P et al (2018) Effects of the replacement of wheat flour with cricket powder on the characteristics of muffins. Acta Sci Pol Technol Aliment 17:227-233. https://doi. org/10.17306/J.AFS.2018.0570

33. Poliszko N, Kowalczewski PŁ, Rybicka I et al (2019) The effect of pumpkin flour on quality and acoustic properties of extruded corn snacks. J Consum Prot Food Saf. https://doi.org/10.1007/ s00003-019-01216-6

34. Kowalczewski PŁ, Walkowiak K, Masewicz $Ł$ et al (2019) Gluten-free bread with cricket powder-mechanical properties and molecular water dynamics in dough and ready product. Foods 8:240. https://doi.org/10.3390/foods 8070240

35. Płowaś-Korus I, Masewicz Ł, Szwengiel A et al (2018) A novel method of recognizing liquefied honey. Food Chem 245:885-889. https://doi.org/10.1016/j.foodchem.2017.11.087

36. Masewicz L, Lewandowicz J, Le Thanh-Blicharz J et al (2016) Diffusion of water in potato starch pastes. In: Proceedings of the 12th international conference on polysaccharides-glycoscience, Prague, pp 193-195

37. Baranowska HM, Masewicz Ł, Kowalczewski PŁ et al (2018) Water properties in pâtés enriched with potato juice. Eur Food Res Technol 244:387-393. https://doi.org/10.1007/s0021 7-017-2965-4

38. Brosio E, Gianferri RR (2009) An analytical tool in foods characterization and traceability. Basic NMR in foods characterization. Research Signpost, Kerala, pp 9-37

39. Baranowska HM (2011) Water molecular properties in forcemeats and finely ground sausages containing plant fat. Food Biophys 6:133-137. https://doi.org/10.1007/s11483-010-9190-z

40. Górnaś P, Juhṇeviča-Radenkova K, Radenkovs V et al (2016) The impact of different baking conditions on the stability of the extractable polyphenols in muffins enriched by strawberry, sour cherry, raspberry or black currant pomace. LWT Food Sci Technol 65:946-953. https://doi.org/10.1016/j.lwt.2015.09.029

41. Kosmala M, Zduńczyk Z, Juśkiewicz J et al (2015) Chemical composition of defatted strawberry and raspberry seeds and the effect of these dietary ingredients on polyphenol metabolites, intestinal function, and selected serum parameters in rats. J Agric Food Chem 63:2989-2996. https://doi.org/10.1021/acs.jafc.5b00648

42. Stephen AM, Champ MM-J, Cloran SJ et al (2017) Dietary fibre in Europe: current state of knowledge on definitions, sources, recommendations, intakes and relationships to health. Nutr Res Rev 30:149-190. https://doi.org/10.1017/S095442241700004X

43. Kim Y, Je Y (2014) Dietary fiber intake and total mortality: a meta-analysis of prospective cohort studies. Am J Epidemiol 180:565-573. https://doi.org/10.1093/aje/kwu174

44. Threapleton DE, Greenwood DC, Evans CEL et al (2013) Dietary fiber intake and risk of first stroke. Stroke 44:1360-1368. https:// doi.org/10.1161/STROKEAHA.111.000151

45. Threapleton DE, Greenwood DC, Evans CEL et al (2013) Dietary fibre intake and risk of cardiovascular disease: systematic review and meta-analysis. BMJ 347:f6879. https://doi.org/10.1136/bmj. f6879
46. Shelton DR, Lee WJ (2000) Cereal carbohydrates. In: Kulp K, Ponte JGJ (eds) Handbook of cereal science and technology, 2nd edn. Marcel Dekker Inc., New York, pp 385-416

47. Isaksson H, Sundberg B, Åman P et al (2008) Whole grain rye porridge breakfast improves satiety compared to refined wheat bread breakfast. Food Nutr Res 52:1809. https://doi.org/10.3402/ $\mathrm{fnr} / \mathrm{v} 52 \mathrm{i} 0.1809$

48. Bresciani L, Scazzina F, Leonardi R et al (2016) Bioavailability and metabolism of phenolic compounds from wholegrain wheat and aleurone-rich wheat bread. Mol Nutr Food Res 60:2343-2354. https://doi.org/10.1002/mnfr.201600238

49. Laatikainen R, Koskenpato J, Hongisto S-M et al (2017) Pilot study: comparison of sourdough wheat bread and yeast-fermented wheat bread in individuals with wheat sensitivity and irritable bowel syndrome. Nutrients 9:1215. https://doi.org/10.3390/nu911 1215

50. Sandvik P, Marklinder I, Nydahl M et al (2016) Characterization of commercial rye bread based on sensory properties, fluidity index and chemical acidity. J Sens Stud 31:283-295. https://doi. org/10.1111/joss.12211

51. Robertson AR (1977) The CIE 1976 color-difference formulae. Color Res Appl 2:7-11. https://doi.org/10.1002/j.1520-6378.1977. tb00104.x

52. Koca AF, Anil M (2007) Effect of flaxseed and wheat flour blends on dough rheology and bread quality. J Sci Food Agric 87:11721175. https://doi.org/10.1002/jsfa.2739

53. Bellary AN, Indiramma AR, Prakash M et al (2016) Anthocyanin infused watermelon rind and its stability during storage. Innov Food Sci Emerg Technol 33:554-562. https://doi.org/10.1016/j. ifset.2015.10.010

54. O'Brien CM, Mueller A, Scannell AGM, Arendt EK (2003) Evaluation of the effects of fat replacers on the quality of wheat bread. J Food Eng 56:265-267. https://doi.org/10.1016/S0260 -8774(02)00266-2

55. Crockett R, Ie P, Vodovotz Y (2011) Effects of soy protein isolate and egg white solids on the physicochemical properties of glutenfree bread. Food Chem 129:84-91. https://doi.org/10.1016/j.foodc hem.2011.04.030

56. Bourne MC (2002) Texture, viscosity, and food. In: Food texture and viscosity. Elsevier, London, pp 1-32

57. Li C, Wang D, Xu W et al (2013) Effect of final cooked temperature on tenderness, protein solubility and microstructure of duck breast muscle. LWT Food Sci Technol 51:266-274. https://doi. org/10.1016/j.lwt.2012.10.003

58. van Nieuwenhuijzen NH, Tromp RH, Mitchell JR et al (2010) Relations between sensorial crispness and molecular mobility of model bread crust and its main components as measured by PTA, DSC and NMR. Food Res Int 43:342-349. https://doi. org/10.1016/j.foodres.2009.10.015

59. Laage D, Stirnemann G, Hynes JT (2010) Water reorientation in the hydration shells of hydrophilic and hydrophobic solutes. Sci China Phys Mech Astron 53:1068-1072. https://doi.org/10.1007/ s11433-010-3215-y

Publisher's Note Springer Nature remains neutral with regard to jurisdictional claims in published maps and institutional affiliations. 